\title{
Non-linear dependencies in African stock markets: Was subprime crisis an important factor?
}

\author{
Paulo Ferreira ${ }^{\mathrm{a}, \mathrm{b}, \mathrm{c}, *}$, Andreia Dionísio $^{\mathrm{a}}$, José Correia ${ }^{\mathrm{a}}$ \\ a CEFAGE-UE, IIFA, Universidade de Évora, Largo dos Colegiais 2, 7000 Évora, Portugal \\ ${ }^{\mathrm{b}}$ Instituto Politécnico de Portalegre, Portalegre, Portugal \\ ${ }^{c}$ VALORIZA - Research Center for Endogenous Resources Valorization, Portalegre, Portugal
}

\section{H I G H L I G H T S}

- It is applied the DFA to analyse the behaviour of 12 African stock indices.

- The results point to the existence of statistically significant serial dependence.

- Dependence is higher in African stock markets, when compared with other indices.

\section{A R T I C L E I N F O}

Article history:

Received 27 November 2017

Received in revised form 13 February 2018

Available online 6 April 2018

Keywords:

African stock markets

Long-term dependence

Hurst exponent

\begin{abstract}
A B S T R A C T
The historical dependence in stock markets it is a very explored issue, especially in developed markets. In this paper we try to address the question of global dependency in African stock markets, and for that purpose we use a global approach able to capture the long-term dependencies being linear or non-linear ones. Are there significant differences in terms of results compared to the major international markets? Results point to an affirmative answer. The Hurst exponent shows that long-term dependence is probably linked not only to size or liquidity.
\end{abstract}

(c) 2018 Elsevier B.V. All rights reserved.

\section{Introduction}

Serial dependence in financial markets is a commonly studied problem in the financial literature. This is important for the issuers of financial assets but also for actual and potential investors, since the knowledge of time patterns may be the basis for arbitrage actions, compromising the possible efficiency of the respective stock market. In fact, there is a close relationship between dependence and efficiency. Besides the fact that efficiency is not the specific theme of this work, it is almost impossible to do not mention the theory its implications. In fact, the subject of market efficiency is not new: at the beginning of the 1970s, Fama [1] stated that returns of financial assets have no memory - this is the Efficient Market Hypothesis (EMH) in its weak form, which implies that return rates should not have any kind of dependence.

Several different tests of serial dependence are found in the finance literature. When using linear autocorrelations, generally those studies conclude that return rates do not suffer from dependence or, if so, even in the short run that dependence disappears (see, for example, [2]). However, when studies involve nonlinear dependences, these could be persistent.

One of the methodologies to analyse nonlinear dependence in data is the use of the Hurst exponent, which could be estimated through different methodologies. One of those methodologies is detrended fluctuation analysis (DFA), able to

\footnotetext{
* Corresponding author at: CEFAGE-UE, IIFA, Universidade de Évora, Largo dos Colegiais 2, 7000 Évora, Portugal.

E-mail addresses: pjsf@uevora.pt (P. Ferreira), andreia@uevora.pt (A. Dionísio), jec@uevora.pt (J. Correia).
} 
detect long-range dependences in time series even if they are non-stationary. If the EMH is verified, return rates behave like a random walk, meaning that they have no memory. However, if we find persistence in a given asset's time series, it could be interpreted as a sign of possible inefficiency. Further studies should prove whether such divergence from the random walk could imply some capacity to predict return rates.

In this paper, we will use the Hurst exponent, derived from DFA, to analyse the behaviour of 12 African stock indices: Botswana, Ivory Coast, Egypt, Kenya, Mauritius, Morocco, Namibia, Nigeria, South Africa, Tunisia, Uganda and Zambia. For each stock market, we analyse the behaviour of the time series from 3rd August 2004 to 13th April 2016, divided in three sub-periods. Furthermore, we are interested in analysing not only the behaviour of each stock market in the whole sample but also to analyse whether the global crisis caused by the Lehman Brothers bankruptcy changed the efficiency pattern of the markets. So we divided the series in three sub-periods: the first sub-period is the "before crisis period" from the 3rd August till 12th September (1074 observations), the second sub-period, the "crisis period", from 15th September to 14th September 2012 (1045 observations); and the third sub-period, the "calm period", from 17th September 2012 till 13th April 2016 (933 observations) and applied DFA again for each series. The cut-off time for the identification of the crisis period was used, among others, by Silva et al. [3].

Although most trading of stocks takes place in the markets of developed countries (mainly USA, European countries and Japan), African markets may show interesting behaviour, (for confirmation, see the results section). In order to compare the behaviour of African markets with other developed indices, we will also analyse the stock indices of Japan, UK and United States and use it as a comparison term.

The main innovation of this research is based on the use of a global approach to evaluate serial dependence in African stock markets, comparing to some developed countries behaviour. Our main results point to the existence of statistically significant serial dependence, in almost all countries, in the period under analysis. This dependence could be caused by the small size and liquidity of those markets.

The remainder of the paper is organized as follows: Section 2 contains a literature review on this topic, concerning studies using both African and non-African stock markets; Section 3 presents the data and the methodology used; Section 4 shows the results; Section 5 concludes and discusses those results.

\section{Serial dependence in stock markets: a brief review}

Speaking about serial dependencies in stock markets is strongly related with the concept of efficiency is its weak form.

Studies analysing the behaviour of financial assets go back more than a century: the study by Bachelier [4], devoted to analysing the probability distribution of stock prices, is one of the studies on this topic (the author concludes on the normality of the data, as expected). Fama [5] explained that in an efficient market, on average, competition will cause the full effects of new information on intrinsic values to be reflected "instantaneously" in actual prices. He concluded that stock market prices follow a random walk. In 1970, Fama, defined an efficient market as "a market whose prices always fully reflect available information is called efficient". Later studies confirm the behaviour of financial markets as random walks, mainly if the linear behaviour of autocorrelations is studied. This is found in older studies (see, for example, [6,7] or [8]) or even in more recent work (see, for example, $[9,10])$.

However, and also with these results, financial markets are found to be affected by some features that the literature calls stylized facts. These facts frequently appear associated with financial data, such as the existence of fat tails in returns, asymmetries between gains and losses, volatility clustering, leverage effect, correlation between trading volumes and volatility or autocorrelation in the variance. These features can be found in several studies and are surveyed, for example, by Cont [11] or Parisi et al. [12].

The use of methodologies that perform not only linear but also nonlinear analysis reveals some of those stylized facts.

Several studies analyse the behaviour of financial markets using nonlinear approaches: Mandelbrot [13], Barkoulas and Baum [14], Darbellay [15], Sadique and Silvapulle [16], Granger et al. [17] or Christodoulou-Volosa and Siokis [18] use different methodologies, studying, for example, fractional analysis, mutual information, measures of entropy, cointegration or scaling analysis. They find common evidence about long-range dependence in financial markets.

The DFA, the methodology used in this paper, is also common in analysing financial data. Although DFA was created to study the behaviour of DNA [19], it was extended to study other phenomena, including the behaviour of financial series. Studies such as Ferreira and Dionísio [9], Kristoufek [20], Cao and Zhang [21] or Anagnostidis et al. [22] are just some examples of relatively recent studies that analyse stock markets using DFA, and also find common evidence of long-term dependence.

Regarding African stock markets, some studies analyse their behaviour through time. The South African stock market is probably the most studied African market, due to it being one of the largest. Smith et al. [23], Smith and Jefferis [24], Magnusson and Wydick [25] or Jefferis and Smith [26] did not find evidence of serial dependence in this particular market. The same studies also analyse other stock indices, finding different results for Botswana, Ghana, Ivory Coast, Egypt, Morocco and Mauritius. The results are corroborated by Mlambo and Biekpe [27] or Smith [28] in these and other African markets (Botswana, Ivory Coast, Egypt, Ghana, Kenya, Mauritius, Morocco, Nigeria, South Africa, Tunisia and Zimbabwe) or by Dickinson and Muragu [29], in Kenya.

Stock market efficiency is detected by Appiah-Kusi and Menyah [30] in some markets: Kenya, Zimbabwe, Egypt, Morocco and Mauritius are examples (curiously, this study points to inefficiency in the South African market). Mlambo and Biekpe 
[31] concluded that contradictory evidence in the random walk tests of certain African stock markets could be partly a methodology problem, especially in a thinly traded market environment. The contradiction in the results, even in cases where the same countries are used, is explained by Smith [28] or Afego [32]: the use of different tests, samples and data frequency could cause these differences. In fact, most of the research finding evidence of efficiency uses linear approaches based on serial correlations. However, as previously mentioned, the existence of nonlinearities could affect the efficiency of financial markets.

For the five largest emerging African stock markets (South Africa, Egypt, Morocco, Nigeria and Zimbabwe) and the US market, Wang et al. [33] studied the long-run relationships and short-run dynamic causal linkages in the period 19962002. They concluded that the interdependence between African markets and the influence of the US on these markets were substantially weakened after the crisis. Ntim et al. [34] studied the weak-form efficiency and made a comparison of 24 African continent-wide stock price indices and those of eight individual African national stock price indices. On average, it was found that irrespective of the test employed, the returns of all the 24 African continent-wide stock price indices examined in the study are less non-normally distributed than the eight individual national stock price indices. The authors also report evidence of African continent-wide stock price indices having significantly better weak-form informational efficiency than their national counterparts.

A deeper survey about the efficiency of African stock markets can be found in Afego [32], who concludes that, results evidence significant serial dependence. The author argues that these results could be related to several issues: the illiquidity of markets, weak investor base, low levels of market capitalization, poor regulation or poor accounting and reporting standards being some of the reasons for those results. Trading costs is another possible explanation for those results [27].

\section{Data and methodology}

The objective of this paper is to analyse the serial dependence in African stock markets, using the Hurst exponent estimated from DFA. Table 1 describes the data used in this study. We retrieved the information for the available indices in DataStream. As mentioned before, the sample starts on 3rd August 2004 and ends on 13th April 2016, with a total of 3052 observations divided in three sub-periods: before crisis period, crisis period and calm period.

In order to achieve our objectives, we will use DFA, analysing the dependence of those indices. The basis of DFA is the concept of the Hurst exponent, an indicator used to distinguish between random or non-random behaviour of time series. It was initially used to determine the randomness in the behaviour of the River Nile and was then generalized to study other natural phenomena. It is also used in financial economics (see, for example, [35]). Basically, a Hurst exponent different from 0.5 contradicts the hypothesis of randomness and, therefore, the efficient market hypothesis.

DFA is a technique that also analyses temporal dependence in time series (with the advantage of being used also in non-stationary time series). Developed by Peng et al. [19], it was originally used to study the behaviour of DNA. However, it has been extended to other research areas, including the behaviour of financial series. The main objective of this technique is to analyse the relationship between values $x_{t}$ and $x_{t+s}$ at different moments in time.

Consider different equidistant observations described by $x_{k}$, with $k=1, \ldots, t$. Firstly, DFA integrates time series, calculating $x(t)=\sum_{k=1}^{t} x_{k}-\langle k\rangle$, with $\langle k\rangle$ the average of the observations (the subtraction of $\langle k\rangle$ is not mandatory because it is eliminated in the third step). Secondly, we divide $x(t)$ in $N / s$ mutual exclusive boxes of equal dimension $s$. Then, a trend $z(t)$ is calculated for each segment, based on ordinary least squares, and the time series is detrended, i.e., performing the following calculation: $x_{s}(t)=x(t)-z(t)$. The original application assumes a linear trend, but later applications show the possibility of including other polynomial trends (see, for example, [36]). For each box, the DFA function is then calculated given by $F(s)=\sqrt{\frac{1}{2 N} \sum_{t=1}^{2 N}\left[x_{s}(t)\right]^{2}}$. Averaging $F(s)$ for all centred boxes in s generates the value of fluctuations $\langle F(s)\rangle$, a function of $s$. This method repeats previous calculations for all different values of $s$. A power-law behaviour is expected of $\langle F(s)\rangle \sim s^{\alpha}$.

This $\alpha$ is equivalent to the Hurst exponent and is used to analyse serial dependence. If $\alpha=0.5$, the time series is represented by a random walk and that time series has no long memory. However, if $\alpha \neq 0.5$, the time series has evidence of long-term correlations in the considered time interval. That long-range dependence is positive, and that series has a persistent behaviour, if $0.5<\alpha<1$. If instead, $\alpha<0.5$, the time series has an anti-persistence behaviour, meaning that larger fluctuations are followed, very likely, by smaller fluctuations (or vice versa). DFA can be analysed graphically using a $\log -\log$ graph for values of $\langle F(s)\rangle$ and for the time scale and making a regression based on ordinary least squares.

We can find some applications of DFA to financial markets. Almost all results point to evidence of long-term dependence. Cizeau et al. [37] analysed the S\&P500 and, although concluding that correlations of returns quickly vanished, their absolute values did not, which was interpreted as nonlinearity in returns' volatility. Ausloos et al. [38] analysed foreign exchange markets (German mark and Polish zloty, against the Belgian franc) and found temporal dependence in these series. Ausloos [39] studied 13 different exchange rates and again found evidence of long-term correlations. Jaroszewicz et al. [40] analysed some Latin American indices, also with evidence of dependence (although as their samples were relatively small, the authors expressed caution in their conclusions). Alvarez-Ramirez et al. [41] evaluated the possibility of forecasting ability in oil prices, concluding that, in short periods of time, they showed some persistence in their correlations (for time spans greater than 25 days, that evidence disappeared). Mariani et al. [42] analysed 26 different stocks of the NYSE and concluded that 19 of them had evidence of long memory (18 with persistent behaviour and only one with anti-persistence). Muchnik et al. [43] analysed the sequence of maxima and minima in stock markets and foreign exchanges and concluded that they present 
Table 1

Indices used in the analysis.

\begin{tabular}{ll}
\hline Stock market & Index \\
\hline Botswana & BSE DCI \\
Ivory Coast & BRVM Composite \\
Egypt & EGX30 \\
Kenya & NSE20 \\
Mauritius & SEMDEX \\
Morocco & Morocco All Share \\
Namibia & FTSE Namibia \\
Nigeria & Nigeria All Share \\
South Africa & JSE40 \\
Tunisia & Tunindex \\
Uganda & USE All Share \\
Zambia & Lusaka All Share \\
Japan & Nikkei 250 \\
UK & FTSE 100 \\
United States & NYSE \\
\hline
\end{tabular}

Table 2

Descriptive statistics for return rates of African stock markets.

\begin{tabular}{|c|c|c|c|c|c|c|}
\hline Stock market & Mean & Std. Dev & Kurtosis & Skewness & Maximum & Minimum \\
\hline Botswana & 0.0004 & 0.0049 & 75.12 & 3.06 & 0.0951 & -0.0477 \\
\hline Ivory Coast & 0.0005 & 0.0086 & 21.87 & -0.29 & 0.0908 & -0.1068 \\
\hline Egypt & 0.0005 & 0.0171 & 7.53 & -0.91 & 0.0731 & -0.1799 \\
\hline Kenya & 0.0001 & 0.0080 & 9.38 & 0.42 & 0.0695 & -0.0523 \\
\hline Mauritius & 0.0003 & 0.0091 & 23.40 & 0.31 & 0.0893 & -0.0814 \\
\hline Morocco & 0.0002 & 0.0079 & 5.43 & -0.32 & 0.0446 & -0.0502 \\
\hline Namibia & 0.0007 & 0.0051 & 77.58 & 5.54 & 0.0808 & -0.0484 \\
\hline Nigeria & -0.00003 & 0.0103 & 3.90 & 0.06 & 0.0798 & -0.0475 \\
\hline South Africa & 0.0005 & 0.0133 & 3.85 & -0.13 & 0.0771 & -0.0796 \\
\hline Tunisia & 0.0005 & 0.0055 & 12.46 & -0.56 & 0.0411 & -0.0500 \\
\hline Uganda & 0.0005 & 0.0147 & 15.73 & 0.08 & 0.1252 & -0.1340 \\
\hline Zambia & 0.0007 & 0.0100 & 12.76 & 0.50 & 0.0942 & -0.0759 \\
\hline Japan & 0.0001 & 0.0151 & 8.58 & -0.49 & 0.1323 & -0.1211 \\
\hline UK & 0.0001 & 0.0117 & 8.43 & -0.16 & 0.0938 & -0.0927 \\
\hline US & 0.0002 & 0.0129 & 11.14 & -0.42 & 0.1153 & -0.1023 \\
\hline
\end{tabular}

long-term correlation (the authors relating this to volatility clustering). Ferreira and Dionísio [9] used DFA for G7 countries plus Greece, Portugal and Spain, and also found evidence of long-term dependence in almost all indices.

Sánchez et al. [44] used the Hurst Exponent estimation to study the behaviour of stocks from the S\&P500 index. They concluded that for the S\&P500 index, in general, stocks do not show persistent memory. Jin [45] used the Hurst exponent for the Asian stock market returns in 2008, during the global financial crisis. He found that for the 2008 period, most returns show a long memory, but when studying calm periods (2005 to 2007 and 2012 to 2014), he did not find a long memory for returns. He concluded that the global financial crisis adversely affected the efficiency of Asian stock markets. He also used the copula models and found there is an important increase in correlation between the local Hurst exponents of several markets, which indicates the presence of financial contagion.

As presented above, there is some literature about the serial dependence in African stock markets. However, as far as we can see, there are no published studies attempting to use DFA as a way to capture global long-term dependencies.

\section{Results}

The objective of this paper is to analyse the behaviour and serial dependences of stock markets. Fig. 1 shows the evolution of stock market indices for all countries. All countries but Nigeria showed an increase in their index value, over the sample. We can also see that most countries had a peak in the sample, almost simultaneously (about 2008). This feature is coherent with the stock markets' crash in that year. This kind of behaviour is not observed in Namibia and Tunisia.

Fig. 2 shows the behaviour of return rates in the indices used. Return rates were calculated as is usual, considering the logarithm different of series in different periods, i.e., $r_{t}=\ln \left(p_{t}\right)-\ln \left(p_{t-1}\right)$, where $r_{t}$ is the return rate at moment $t$ and $p_{t}$ the index value at the same moment. Regarding to African markets, a quick look at the graphs reveals that some indices are more volatile (for example, Egypt, South Africa, Uganda and Zambia) and others have less fluctuation (Botswana, Namibia and Tunisia).

Table 2 contains descriptive statistics of the stock markets, which obviously confirm our previous findings.

First, it is possible to conclude that, except for the Nigerian index, all the countries have return rates with a positive mean (all of them increased their values). The information about the standard deviation informs us about the volatility of the index, 

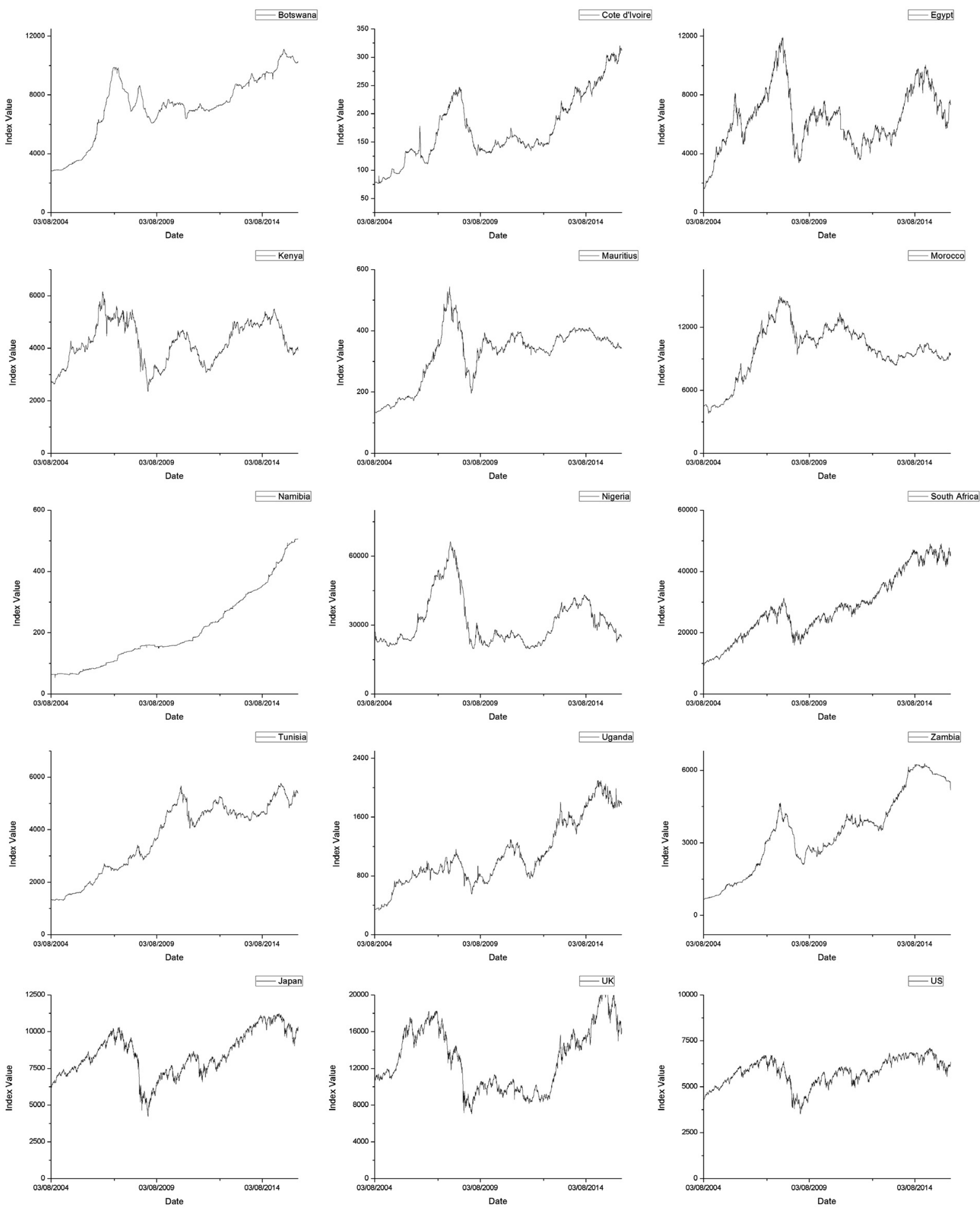

Fig. 1. Stock market indices values.

which could be complemented with analysis of the extreme values of return rates. Another interesting feature of that table is the fact that all distributions have relatively high kurtosis values. This means that the distribution of return rates of each of these stock markets is leptokurtic, consistent with the existence of fat tails, identified as a stylized fact of financial markets 

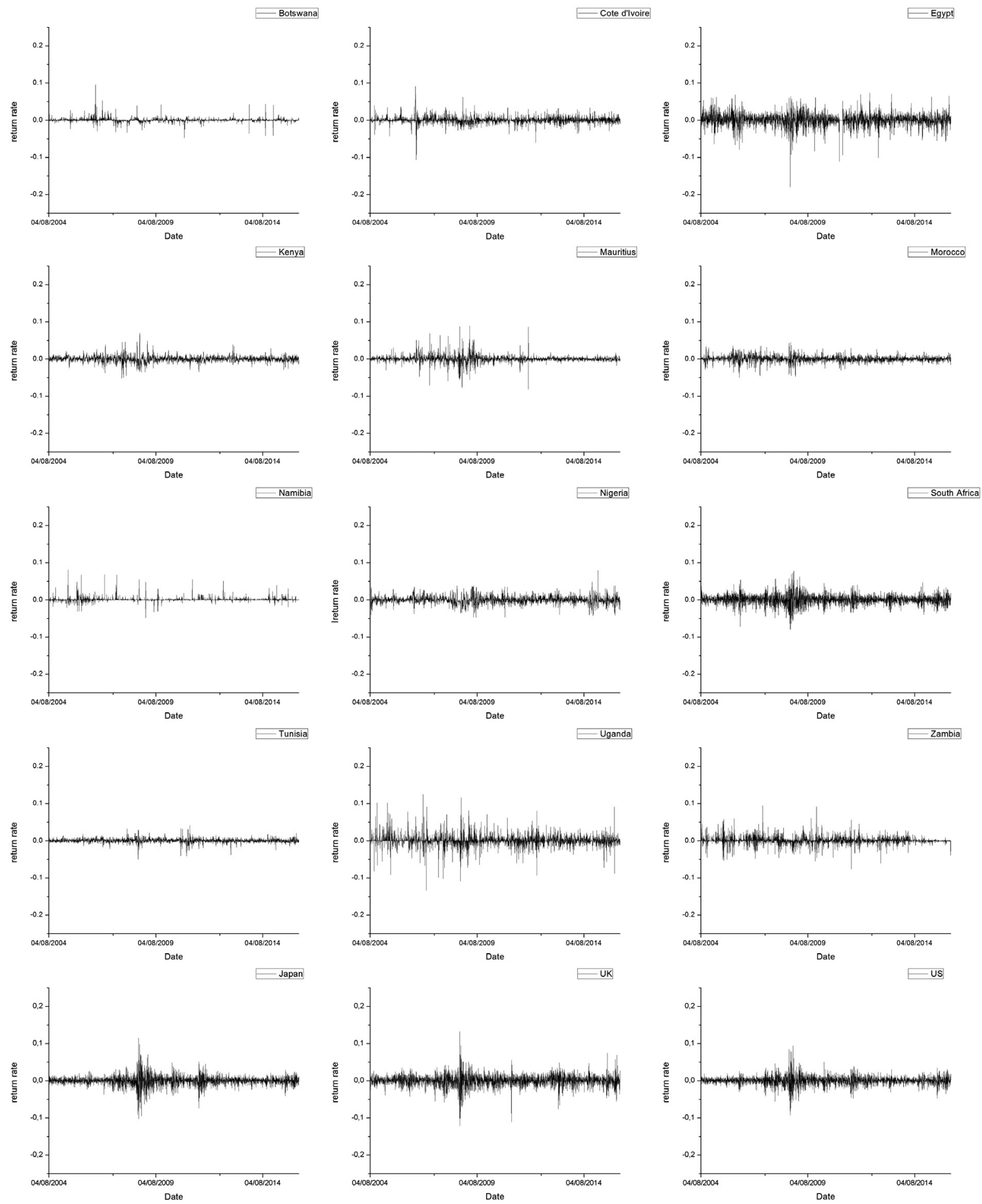

Fig. 2. Stock market indices return rates.

(see, for example, [11]). Regarding skewness, results are mixed, with five African indices and the ones of Japan, UK and US showing negative values, meaning that occurred more extremely negative than positive ones. Seven of the African indices 
Table 3

DFA results. The hypotheses are H0: $\alpha=0.5$ and $\mathrm{H} 1 \alpha \neq 0.5$.

\begin{tabular}{|c|c|c|c|}
\hline Stock market & DFA exponent (before crisis) & DFA exponent (crisis period) & DFA exponent (calm period) \\
\hline Botswana & $0.6035 \pm 0.0201^{* *}$ & $0.6679 \pm 0.0077^{* *}$ & $0.5717 \pm 0.0156^{* * *}$ \\
\hline Ivory Coast & $0.6028 \pm 0.0061^{* *}$ & $0.5135 \pm 0.0066$ & $0.4970 \pm 0.0030$ \\
\hline Egypt & $0.5171 \pm 0.0025^{* *}$ & $0.6679 \pm 0.0077^{* * *}$ & $0.4492 \pm 0.0166^{* *}$ \\
\hline Kenya & $0.5660 \pm 0.0097^{* * *}$ & $0.5701 \pm 0.0140^{* * *}$ & $0.5318 \pm 0.0100^{* * *}$ \\
\hline Mauritius & $0.5134 \pm 0.0049^{*}$ & $0.5285 \pm 0.0056^{*}$ & $0.5519 \pm 0.0067^{* *}$ \\
\hline Morocco & $0.5476 \pm 0.0036^{* *}$ & $0.4515 \pm 0.0050^{* * *}$ & $0.5459 \pm 0.0093^{* *}$ \\
\hline Namibia & $0.4915 \pm 0.0058$ & $0.4016 \pm 0.0070$ & $0.3646 \pm 0.0070^{* *}$ \\
\hline Nigeria & $0.5500 \pm 0.0123^{* * *}$ & $0.6183 \pm 0.0059^{* * *}$ & $0.5319 \pm 0.0108^{* *}$ \\
\hline South Africa & $0.3928 \pm 0.0075^{* *}$ & $0.3136 \pm 0.0103^{* * *}$ & $0.4020 \pm 0.0045^{* *}$ \\
\hline Tunisia & $0.5938 \pm 0.0031^{* *}$ & $0.5190 \pm 0.0069^{*}$ & $0.5578 \pm 0.0019^{* *}$ \\
\hline Uganda & $0.4564 \pm 0.0029^{* * *}$ & $0.4764 \pm 0.0071^{* *}$ & $0.4313 \pm 0.0060^{* *}$ \\
\hline Zambia & $0.4727 \pm 0.0156$ & $0.5312 \pm 0.0067^{* *}$ & $0.3877 \pm 0.0027^{* *}$ \\
\hline Japan & $0.4875 \pm 0.0031^{* *}$ & $0.4839 \pm 0.0018^{* *}$ & $0.5236 \pm 0.0039^{* *}$ \\
\hline UK & $0.4987 \pm 0.0072$ & $0.4688 \pm 0.0019^{* * *}$ & $0.4889 \pm 0.0110$ \\
\hline US & $0.5022 \pm 0.0048$ & $0.4641 \pm 0.0016^{* * *}$ & $0.4856 \pm 0.0111$ \\
\hline
\end{tabular}

" Denotes rejection of the null hypothesis for a $1 \%$ significance level.

** Denotes rejection of the null hypothesis for a $1 \%$ significance level.

show the contrary evidence (for example, for almost of those markets, the maximum value is greater, in absolute value, than the minimum one).

After calculating descriptive statistics, we applied DFA to the three sub-periods under analysis for stock returns, the results being presented in Table 3, in the second column. The second column shows the result of the exponent before the Lehman Brothers episode, the third column the "crisis period" and the fourth column the "calm period". As referred to in the methodology, return rates are expected to show an exponent value around 0.5. With the results of the DFA, it is possible to test statistically if a given exponent is equal to or different from 0.5 , with a simple t-test. In this way we test for the absence of long memory in those series. The results of the tests are also presented in Table 3.

In general terms, results show a trend to stronger levels of long memory (persistent or anti-persistent) from the period before crisis to the crisis one; and also, some recuperation or stabilization in the calm period. Of course, there are exceptions. See for example Zambia and Namibia, which Hurst exponent values after crisis, in the calm period, move a way (in a significant way) from 0.5 . The small levels of liquidity and lower transaction volumes could be the cause of that depart from the efficiency, or that least from the absence of long memory.

On the contrary, the expected behaviour is well established in the 3 developed markets used as comparison: Japan, UK and US.

Results also show that African markets exhibit long memory in the 3 sub-periods under study, being observed an increase of memory in the crisis period. Somehow, these results are expectable and understandable and corroborate most of the literature in this area (see, for example, [46,47]).

\section{Conclusions}

This main goal of this paper is to analyse the efficiency of African stock markets, using the Hurst exponent to evaluate serial dependence. This method was selected taking into account its advantages in terms of globalism, absence of strict assumptions and simplicity of interpretation. Daily stock indices of the following countries were analysed: Botswana, Ivory Coast, Egypt, Kenya, Mauritius, Morocco, Namibia, Nigeria, South Africa, Tunisia, Uganda and Zambia. In order to compare results we also include in the analysis UK, USA and Japan.

To gain a clearer notion of serial dependence, the whole period under review (3rd August 2004 to 13th April 2016) was generally considered, with this being divided in three sub-periods: pre-crisis, crisis and calm period.

Overall, the results point to the existence of statistically significant (persistent and anti-persistent) serial dependence. These results are confirmed in the majority of countries under review, in both the whole period and the sub-periods. When comparing with the non-African indices, in these countries exist evidence of serial independence in the period before Lemon Brothers incident, and, when is detected any kind of dependence, it is less significant than in the majority of the African indices.

The possible signal of long-term dependence in the analysed markets may be linked to a lack of liquidity and the small size of these markets. They are therefore markets where speculation and manipulation of assets may be potentiated.

\section{Acknowledgement}

The authors are pleased to acknowledge financial support from Fundação para a Ciência e a Tecnologia and FEDER/ COMPETE (grant PEst-C/EGE/UI4007/2013). 


\section{References}

[1] E. Fama, Efficient capital markets: A review of theory and empirical work, J. Finance 25 (1970) 383-417.

[2] G. Bonanno, F. Lillo, R. Mantegna, Levels of complexity in financial markets, Physica A 299 (2001) 16-27.

[3] M. Silva, E. Pereira, A. Filho, A. Castro, J. Miranda, G. Zebende, Quantifying the contagion effect of the 2008 financial crisis between the G7 countries (by GDP nominal), Physica A 453 (2016) 1-8.

[4] L. Bachelier, Theory of speculation, in: P. Cootner (Ed.), The Random Character of Stock Prices, MIT Press, Cambridge, 1964 originally published in 1900.

[5] E. Fama, The behavior of stock-market prices, J. Bus. 38 (1) (1965) 34-105.

[6] M. Kendall, The analysis of economic time-series, J. Roy. Statist. Soc. 116 (1953) 11-25.

[7] M. Osborne, Brownian motion in the stock prices, in: P. Cootner (Ed.), The Random Character of Stock Prices, MIT Press, Cambridge, 1964 originally published in 1959.

[8] C. Granger, O. Morgenstein, Spectral analysis of New York stock market prices, in: P. Cootner (Ed.), The Random Character of Stock Prices, MIT Press, Cambridge, 1964 originally published in 1963.

[9] P. Ferreira, A. Dionísio, Revisiting serial dependence in the stock markets of the G7 countries, Portugal, Spain and Greece, Appl. Financ. Econ. 24 (2014) 319-331.

[10] P. Ferreira, A. Dionísio, How long is the memory of the US stock market? Physica A 451 (2016) 502-506.

[11] R. Cont, Empirical properties of asset returns: Stylized facts and statistical issues, Quant. Finance I (2001) 223-236.

[12] D. Parisi, D. Sornett, D. Helbing, Financial price dynamics and pedestrian counterflows: A comparison of statistical stylized facts, Phys. Rev. E 87 (2013) 012804

[13] B. Mandelbrot, The fractal geometry of nature, Freeman, New York, 1977.

[14] J. Barkoulas, C. Baum, Long-term dependence in stock returns, Econom. Lett. 53 (1996) 253-259.

[15] G. Darbellay, Predictability: an information-theoretic perspective, in: A. Procházka, J. Uhlír, P. Rayner, N. Kingsbury (Eds.), Signal Analysis and Prediction, Birkhauser, Boston, 1998, pp. 249-262.

[16] S. Sadique, P. Silvapulle, Long-term memory in stock market returns: international evidence, Int. J. Financ. Econ. 6 (2001) 59-67.

[17] C. Granger, E. Maasoumi, J. Racine, A Dependence metric for possibly nonlinear processes, J. Time Series Anal. 25 (2004) 649-669.

[18] C. Christodoulou-Volosa, F. Siokis, Long range dependence in stock market returns, Appl. Financ. Econ. 16 (2006) 1331-1338.

[19] C. Peng, S. Buldyrev, S. Havlin, M. Simons, E. Stanley, A. Goldberger, Mosaic organization of DNA nucleotides, Phys. Rev. E 49 (1994) 1685-1689.

[20] L. Kristoufek, Detrended fluctuation analysis as a regression framework: Estimating dependence at different scales, Phys. Rev. E 91 (2015) 022802.

[21] G. Cao, M. Zhang, Extreme values in the Chinese and American stock markets based on detrended fluctuation analysis, Physica A 436 (2015) 25-35.

[22] P. Anagnostidis, C. Varsakelis, C. Emmanouilides, Has the 2008 financial crisis affected stock market efficiency? The case of Eurozone, Physica A 447 (2016) 116-128.

[23] G. Smith, K. Jefferis, H. Ryoo, African stock markets: Multiple variance ratio tests of random walks, Appl. Financ. Econ. J. 12 (2002) 475-484.

[24] G. Smith, K. Jefferis, The evolving efficiency of African stock markets. Unpublished research paper, in: School of Oriental and African Studies, University of London, 2002

[25] M. Magnusson, B. Wydick, How efficient are Africa's emerging stock markets? J. Dev. Stud. 38 (2002) 141-156.

[26] K. Jefferis, G. Smith, The changing efficiency of African stock markets, South Afr. J. Econ. 73 (2005).

[27] C. Mlambo, N. Biekpe, The efficient market hypothesis: Evidence from ten African stock markets, Invest. Anal. J. 66 (2007) 5-17.

[28] G. Smith, Liquidity and the informational efficiency of African stock markets, South Afr. J. Econ. 76 (2008).

[29] J. Dickinson, K. Muragu, Market efficiency in developing countries: A case study of the Nairobi Stock Exchange, J. Bus. Account. 21 (1994) $133-150$.

[30] J. Appiah-Kusi, K. Menyah, Return predictability in African stock markets, Rev. Financ. Econ. 12 (2003) 247-270.

[31] C. Mlambo, N. Biekpe, Thin-trading on African stock markets: Implications on market efficiency testing, Invest. Anal. J. 61 (2005) 29-40.

[32] P. Afego, Market efficiency in developing African stock markets: What do we know? J. Dev. Areas 49 (2015).

[33] Z. Wang, J. Yang, D. Bessler, Financial crisis and African stock market integration, Appl. Econ. Lett. 10 (2003) 527-533.

[34] C. Ntim, K. Opong, J. Danbolt, F. Dewotor, Testing the weak-form efficiency in African stock markets, Manage. Finance 37 (2011) 195-218.

[35] E. Peters, Chaos and order in the capital markets, Wiley, 1996.

[36] J. Kantelhardt, E. Koscielny-Bunde, H. Rego, S. Havlin, A. Bunde, Detecting longrange correlations with detrended fluctuation analysis, Physica A 295 (2001) 441-454.

[37] P. Cizeau, Y. Liu, M. Meyer, C. Peng, H. Stanley, Correlations in Economic Time Series. arXiv:cond-mat/9706021v1, 1997.

[38] M. Ausloos, N. Vandewalle, P. Boveroux, A. Minguet, K. Ivanova, Applications of statistical physics to economic and financial topics, Physica A 274 (1999) 229-240.

[39] M. Ausloos, Statistical physics in foreign exchange currency and stock markets, Physica A 285 (2000) 48-65.

[40] S. Jaroszewicz, M. Mariani, M. Ferraro, Long correlations and truncated Levy walks applied to the study Latin-American market indices, Physica A 355 (2005) 461-474.

[41] J. Alvarez-Ramirez, J. Alvarez, E. Rodriguez, G. Fernandez-Anaya, Time-varying Hurst exponent for US stock markets, Physica A 387 (2008) $6159-6169$.

[42] M. Mariani, I. Florescu, M. Varela, E. Ncheuguima, Long correlations and Levy models applied to the study of memory effects in high frequency (tick) data, Physica A 388 (2009) 1659-1664.

[43] L. Muchnik, A. Bunde, S. Havlin, Long term memory in extreme returns of financial time series, Physica A 388 (2009) 4145-4150.

[44] M. Sánchez, J. Trinidad, J. Garcia, M. Fernández, The Effect of the underlying distribution in Hurst exponent estimation, PLoS One 10 (2015) e0127824.

[45] X. Jin, The impact of 2008 financial crisis on the efficiency and contagion of Asian stock markets: A Hurst exponent approach, Finance Res. Lett. 17 (2016) $167-175$.

[46] D. Cajueiro, B. Tabak, Evidence of long range dependence in Asian equity markets: the role of liquidity and market restrictions, Physica A 342 (2004) 656-664

[47] D. Cajueiro, B. Tabak, The Hurst exponent over time: Testing the assertion that emerging markets are becoming more efficient, Physica A 336 (2004) 521-537. 